\title{
Palmoplantar keratoderma-XX sex reversal-predisposition to squamous cell carcinoma syndrome
}

INSERM

\section{Source}

INSERM. (1999). Orphanet: an online rare disease and orphan drug data base.

Palmoplantar keratoderma-XX sex reversal-predisposition to squamous cell carcinoma

syndrome. ORPHA:85112

Palmoplantar keratoderma-XX sex reversal-predisposition to squamous cell carcinoma syndrome is characterised by sex reversal in males with a 46, XX (SRY-negative) karyotype, palmoplantar hyperkeratosis and a predisposition to squamous cell carcinoma. To date, five cases (four of whom were brothers) have been described. The aetiology is unknown. 